\title{
Evaluating effectiveness of screening house eaves as a potential intervention for reducing indoor vector densities and malaria prevalence in Nyabondo, western Kenya
}

Peter Njoroge Ng'ang'a $a^{1,2^{*}}$ (0, Collins Okoyo ${ }^{3}$, Charles Mbogo ${ }^{3,4}$ and Clifford Maina Mutero ${ }^{1,5}$

\begin{abstract}
Background: Mosquito-proofing of houses using wire mesh screens is gaining greater recognition as a practical intervention for reducing exposure to malaria transmitting mosquitoes. Screening potentially protects all persons sleeping inside the house against transmission of mosquito-borne diseases indoors. The study assessed the effectiveness of house eaves screening in reducing indoor vector densities and malaria prevalence in Nyabondo, western Kenya.

Methods: 160 houses were selected for the study, with half of them randomly chosen for eaves screening with fibreglass coated wire mesh (experimental group) and the other half left without screening (control group). Randomization was carried out by use of computer-generated list in permuted blocks of ten houses and 16 village blocks, with half of them allocated treatment in a ratio of 1:1. Cross-sectional baseline entomological and parasitological data were collected before eave screening. After baseline data collection, series of sampling of indoor adult mosquitoes were conducted once a month in each village using CDC light traps. Three cross-sectional malaria parasitological surveys were conducted at three month intervals after installation of the screens. The primary outcome measures were indoor Anopheles mosquito density and malaria parasite prevalence.

Results: A total of 15,286 mosquitoes were collected over the two year period using CDC light traps in 160 houses distributed over 16 study villages (mean mosquitoes $=4.35, \mathrm{SD}=11.48$ ). Of all mosquitoes collected, 2,872 (18.8\%) were anophelines (2,869 Anopheles gambiae sensu lato, 1 Anopheles funestus and 2 other Anopheles spp). Overall, among An. gambiae collected, $92.6 \%$ were non-blood fed, $3.57 \%$ were blood fed and the remaining $0.47 \%$ were composed of gravid and half gravid females. More indoor adult mosquitoes were collected in the control than experimental arms of the study. Results from cross-sectional parasitological surveys showed that screened houses recorded relatively low malaria parasite prevalence rates compared to the control houses. Overall, malaria prevalence was 5.6\% ( $95 \%$ Cl: $4.2-7.5) n=1,918$, with baseline prevalence rate of $6.1 \%$ (95\% Cl: 3.9-9.4), $n=481$ and $3^{\text {rd }}$ follow-up survey prevalence of $3.6 \%(95 \% \mathrm{Cl}: 2.0-6.8) \mathrm{n}=494$. At all the three parasitological follow-up survey points, house screening significantly reduced the malaria prevalence by $100 \%(p<0.001), 63.6 \%(p=0.026)$, and $100 \%(p<0.001)$ in the 1 st, 2nd and 3rd follow-up surveys respectively.
\end{abstract}

*Correspondence: pnganga2003@gmail.com; peter.nganga@jkuat.ac.ke

${ }^{1}$ International Centre of Insect Physiology and Ecology (ICIPE), PO

Box 30772, Nairobi, Kenya

Full list of author information is available at the end of the article

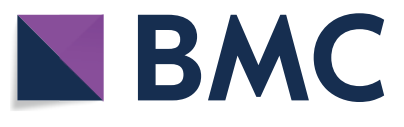

(c) The Author(s) 2020. This article is licensed under a Creative Commons Attribution 4.0 International License, which permits use, sharing, adaptation, distribution and reproduction in any medium or format, as long as you give appropriate credit to the original author(s) and the source, provide a link to the Creative Commons licence, and indicate if changes were made. The images or other third party material in this article are included in the article's Creative Commons licence, unless indicated otherwise in a credit line to the material. If material is not included in the article's Creative Commons licence and your intended use is not permitted by statutory regulation or exceeds the permitted use, you will need to obtain permission directly from the copyright holder. To view a copy of this licence, visit http://creativeco mmons.org/licenses/by/4.0/. The Creative Commons Public Domain Dedication waiver (http://creativecommons.org/publicdomain/ zero/1.0/) applies to the data made available in this article, unless otherwise stated in a credit line to the data. 
Conclusions: The study demonstrated that house eave screening has potential to reduce indoor vector densities and malaria prevalence in high transmission areas.

Keywords: Anopheles gambiae, Eaves, Screening, Malaria, Prevalence, Mosquitoes, Vector control

\section{Background}

Malaria remains a major public health problem in Kenya, accounting for approximately $21 \%$ of outpatient consultations and $3-5 \%$ of hospital admissions each year [1]. The disease prevalence in the country varies by season and across geographic regions [2,3]. Areas in the western and eastern parts of the country, respectively around Lake Victoria and at the coast, present the highest risk with children under five years and pregnant women being the most vulnerable to infection [4]. The Government of Kenya places a high priority on malaria prevention and control, with eventual malaria elimination listed as one of the strategic objectives of the Kenya Health Policy [1].

Through the Ministry of Health (MOH), the National Malaria Control Programme (NMCP) has implemented sound policies and evidence-based strategies in the fight against malaria. Key interventions include the provision of long-lasting insecticidal nets (LLINs), intermittent preventive treatment for pregnant women, and prompt diagnosis and effective treatment of all malaria cases with appropriate drugs, particularly artemisininbased combination therapy [1,4]. Other interventions include improving the capacity of health providers and strengthening the supply chain to deliver diagnostic tests and quality-assured medicines at all levels of the health system.

Vector control is among the widely recognized effective measures for prevention of malaria transmission and it constitutes a core strategy for malaria control in the African region $[4,5]$. The most common vector control options are LLINs, and indoor residual spraying (IRS) using insecticides approved by the WHO Pesticide Evaluation Scheme (WHOPES) [6, 7]. The two insecticidebased methods although regarded as being among the key factors that contributed to $50-60 \%$ global reduction of malaria between 2000 and 2015 are faced with serious challenges, most notably widespread insecticide resistance among mosquito populations [8-11]. The World Health Organization's response to these perennial challenges includes the promotion of integrated vector management (IVM), involving combining of existing primary interventions of LLINs and IRS with complementary methods, such as house improvements and other environmental management measures [12-15].

Historically, destruction of vector breeding habitat, application of IRS using insecticides, such as Dichlorodiphenyltrichloroethane (DDT) and improvement of housing structures have been shown to reduce indoor vector densities and malaria transmission [16-18]. The interventions have in the past significantly contributed to suppression or elimination of malaria and yellow fever. In the early twentieth century, screening and improvements in housing helped bring about marked reductions in malaria across different settings, most notably in the USA $[16,19]$.

Mosquito-proofing of houses is particularly important because the main Anopheles species of mosquitoes transmitting malaria in Africa bite between dusk and dawn when people are asleep indoors. They enter human dwellings through open windows, doors and eaves, largely attracted by human odour [20]. Open eaves are significant entry points into houses for malaria vector species and are recognized as a risk factor for malaria transmission in endemic regions [21]. Therefore, housing improvement incorporating screening as a physical barrier against mosquito entry is potentially an effective mechanism of reducing malaria transmission. This fact was also recognized by the Roll Back Malaria (RBM) Vector Working Group and its partners in their November 2015 consensus statement on housing and Malaria [22]. The statement argues that while traditional preventive measures, such as treated mosquito nets and insecticide spraying has greatly contributed in lowering malaria incidence and deaths, they need to be complemented by other measures of malaria control and elimination, such as house screening because it covers and protects all individuals in a house equally [20,22].

Perhaps the most obvious way of preventing mosquitoes from entering a house is to screen the entry points with a mesh. A trial of house screening in The Gambia showed that screening led to a reduction in the number of mosquitoes entering houses and in the prevalence of anaemia in children [23]. Among the potential advantages of house screening is the equity with which it protects all members of the household at all times while indoors $[24,25]$, unlike LLINs which primarily give protection to those with a net during sleeping hours only. An additional benefit of house screening is its potential for integration with other vector control and disease management interventions, offering protection from both malaria and other vector borne diseases such as lymphatic filariasis [26, 27].

Recent systematic reviews and meta-analysis [21, 24, 25 ] have underscored the need for further studies on 
housing improvements in Africa and other parts of the tropics. Additional research can give clarity regarding situations in which house screening is an effective malaria intervention, since certain studies have shown that screening can be effective in preventing mosquito entry into houses, but with little evidence as to how much it can reduce malaria infection [28].

The systematic reviews have also highlighted the absence of data from many geographical regions, lack of enough intervention studies and the high risk of bias within and across studies [21, 25, 27]. Progress towards building the required body of scientific evidence includes a randomized controlled trial (RCT), conducted in the Gambia, which evaluated a house screening intervention against malaria, epidemiological outcomes and social acceptability $[23,29]$.

A recent survey on community perceptions and knowledge regarding the protective nature of house screening in the study area showed that more than $85 \%$ of household owners considered screening useful, although majority of houses in the area were not screened [29]. Reasons given for not screening the houses included perceptions that it was costly, and also lack of awareness regarding its effectiveness in protecting against malaria. The objective of this study was to evaluate the effectiveness of house-eaves screening in reducing both indoor resting malaria vector densities and malaria prevalence.

\section{Methods}

\section{Study area}

The study was carried out in Nyabondo, a plateau area located in Upper Nyakach sub-county of Kisumu County, about $30 \mathrm{~km}$ North-East of Lake Victoria. Nyabondo lies between an altitude of $1520 \mathrm{~m}$ and $1658 \mathrm{~m}$ above sea level, and $0^{\circ} 23^{\prime} 0 \mathrm{~S}$ and $34^{\circ} 58^{\prime} 60 \mathrm{E}$. The area is host to an estimated 34,000 people with a high population density of nearly 460 persons per square kilometre $(\mathrm{km})$ [31]. The community largely depends on brick making as the main economic activity with small-scale mixed farming activities such as crop/fish farming and livestock keeping. Agricultural activities are dominated by crops such as maize, cassava, sorghum and sweet potatoes [15, 32]. Malaria is endemic in this region and its perennial transmission is mainly determined by rainfall, temperature and humidity $[4,33]$. The reported average malaria parasite prevalence in the human population was about $27 \%$ in 2015 [1, 4, 33]. Previous entomological surveys in Nyabondo found that larval Anopheles mosquitoes bred in both temporary and permanent aquatic habitats with Anopheles arabiensis being the main malaria vector species (99.3\%), followed by Anopheles gambiae (0.7\%) [32, 34 , 35]. In 2015/2016, the overall poverty headcount rate for individuals at the national level was $36.1 \%$. The highest overall poverty incidence nationally was reported in rural areas, where $40.1 \%$ of the residents were considered as overall poor, compared to $27.5 \%$ in peri-urban areas and $29.4 \%$ in core urban areas [36]. Being a rural setup, the overall poverty incidence in Nyabondo was approximated at $40.1 \%$ [36]. The majority of houses in Nyabondo are made up of local design, constructed with iron sheets roofs, mud walls and a plaster finishing walls (Fig. 1) made by mixing ash, mud and cow dung [30].

\section{Study design}

A cluster randomized study design was implemented to study the effect of house eaves screening $[37,38]$. An initial household enumeration exercise was conducted and randomization carried out by use of computer-generated list, in permuted blocks of ten houses and 16 village blocks in the study site, with 80 houses in each of the two study arms (control and intervention) for both entomological and parasitological assessment. In each village, there were 10 houses randomly selected for the study with half of them allocated treatment in a ratio of 1:1 between the control and treatment groups. Considering the high average malaria prevalence (27\%) normally reported in Nyabondo, and since the area is not vast geographically, being as it is within a sub-county, it was assumed that the population sampled from a total of 160 households would constitute a large enough sample capable of showing valid statistical difference in the measurements being taken.

\section{Entomological surveys}

Sampling of adult mosquitoes was conducted from January 2017 to November 2018. The sampling was spread out over a period of 16 days each month, with all the ten

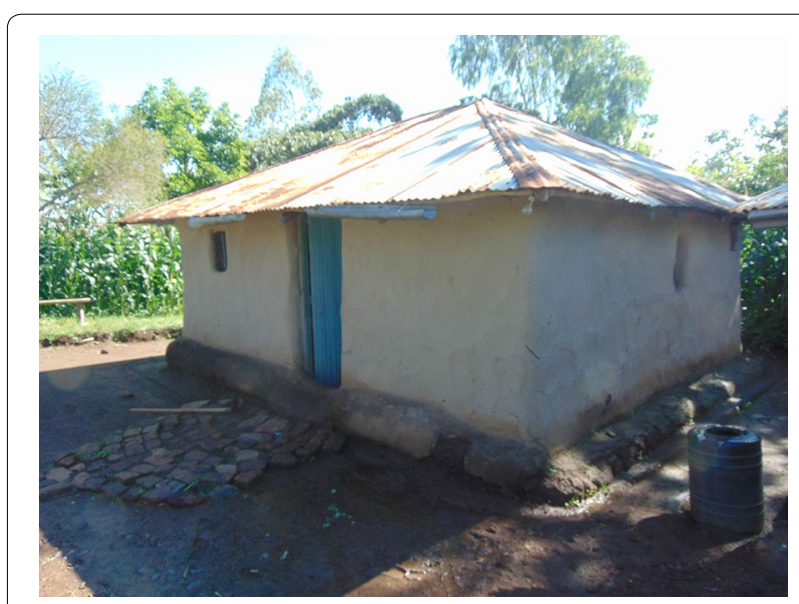

Fig. 1 An ordinary local house in the study area showing the wall and the roofing type 
houses in a particular village being sampled in one night. Sampling was conducted using CDC light traps with one light trap set up in an occupied bedroom per house and left to run for $12 \mathrm{~h}$ overnight between 19:00hours and 07:00hours. Mosquitoes collected in the morning were killed using chloroform and morphologically identified in the field station as either belonging to anopheline or culicine group [39, 40]. Subsamples of anophelines were also identified morphologically to species and sex and further separated by physiological state as either unfed and blood fed using keys of Gillies and De Meillon [40]. Adult mosquito collections were done simultaneously for two years in both intervention and control houses and were scheduled so as to span both dry and wet seasons. The number of female indoor adult An. gambiae sensu lato (s.l.) vectors collected per trap night were used as a primary outcome for assessing the efficacy of eave screening in reducing indoor malaria vector densities.

\section{Malaria prevalence surveys}

Cross-sectional household malaria parasitological surveys were conducted after every three months from September 2017 to November 2018. Testing was done by Rapid Diagnostic Tests (RDTs), using SD-Bioline malaria antigen P. $\mathrm{f}^{\circledR}$ test as recommended by the NMCP in Kenya [41]. All members of the household were tested for the presence of malaria parasite using RDT [42] for four consecutive times (i.e. in every three months), this included one baseline survey in September 2017. The tests were performed by trained staff from the Ministry of Health following the manufacturer instructions $[41,42]$. Individual socio-demographic information of the household members were collected in addition to the house characteristics. Consent to participate in this study was requested from the participants during the study. Individuals were asked whether they had taken any anti-malaria medication prior to the survey day. Participants found to be positive for malaria parasites were treated by Ministry of Health staff according to World Health Organization (WHO) and National Guidelines for the Diagnosis, Treatment and Prevention of Malaria in Kenya [41-43]. Malaria parasite rate was used as the secondary endpoint for assessing the efficacy of eave screening at household level.

\section{Eave screening procedure}

After randomization and getting consent from household owners, the houses in the category to be screened were fitted with grey coloured fibre-glass coated wire mesh, designed to tightly and firmly fit onto pre-measured eave openings. Prior to fixing the screen in NovemberDecember 2017, an elastic cloth lining was sewn onto its edges by a tailor hired from the community. The lining is what was used to fix the screen on a wooden framework in the house eaves using one inch nails $(2.54 \mathrm{~cm})$ as a harness (Fig. 2). The screening work and roll-out roster was undertaken by project staff together with local youth, trained by an experienced consultant who had previous experience with house screening in other similar areas. During the screening activities, household occupants were encouraged to close windows and doors early in the evening in order to reduce mosquito entry into houses. Both Informed, verbal and written consent were sought
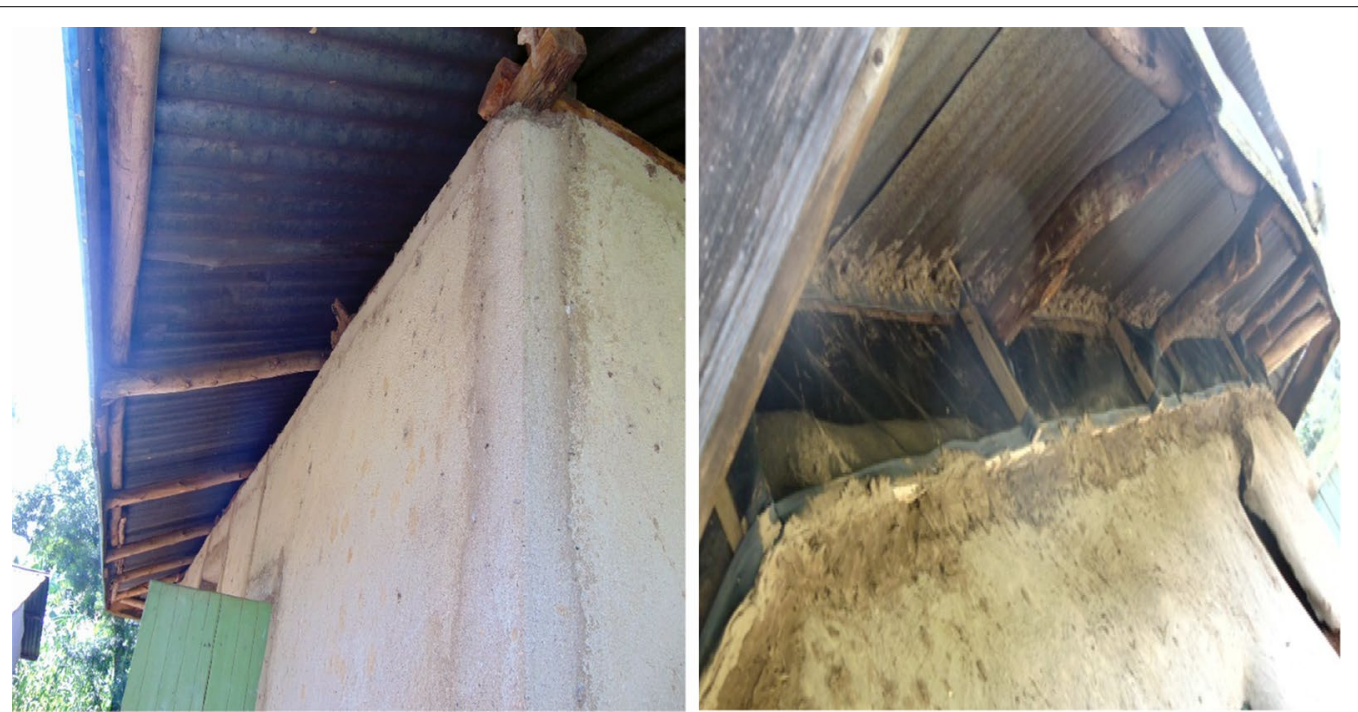

Fig. 2 An ordinary house showing unscreened open eave on the left and a similar house on the right fitted with grey polyester netting material [screened eave] 
from the head of each household before screens were installed into houses.

\section{Health facility data collection}

Data on laboratory confirmed malaria cases was collected from the area mission health facility in Nyabondo and recorded every month during 2017-2018 period. A data collection form was developed and used to capture this information. Malaria case detection form was used to summarize cases based on age, gender and home locality of the patient. Health-seeking in the area is primarily from $\mathrm{MOH}$ and faith-based facilities such as the mission health facility in Nyabondo since they are either free or charge minimal user fees for their services.

\section{Rainfall data}

Rainfall data was obtained from the local meteorological department situated within the study area. Monthly average rainfall for the two years was computed and used in the analysis.

\section{Data management and statistical analysis}

Data collected was counter-checked for accuracy and verified before double entry into computer MS Excel spreadsheet. The double entry was done by an independent person, who also checked for data entry errors. Adult mosquito relative density was defined as the number of female adult Anopheles mosquitoes per house per night. The 95\% confidence intervals (CIs) for the mean adult mosquito relative density were estimated using negative binomial regression model adjusted for household clusters. Mean mosquito population densities and the relative abundance of different vector species were compared between 2017 and 2018. The effect of house screening intervention on adult mosquito density was estimated using generalized estimating equations (GEE) [44], allowing for within-subject correlation using robust variance estimator to calculate standard errors (SEs). From the GEE model, we reported the incidence rate ratios (IRRs), the control arm (unscreened houses) was used as the reference against the experimental (screened houses).

For malaria epidemiological survey, Plasmodium falciparum infection was defined as a positive rapid diagnostic test (RDT) result. Proportion of individuals infected with malaria was calculated and the 95\% confidence intervals (CIs) estimated using binomial regression model that accounted for household clusters. The impact of house screening on infection prevalence was calculated and odds ratios (ORs) estimated using multilevel mixed effects logistic regression model while accounting for household clusters. All statistical analyses were performed using STATA version 14.1.

\section{Results}

\section{Characteristics of study population}

In total, 160 households participated in both entomological and parasitological surveys. Around thirty two percent $(31.9 \%)$ of the study household heads/spouses had completed primary school education and $16.9 \%$ had dropped out at secondary schools. In terms of occupation, majority of the household (91.9\%) were farmers, 5\% in self business and $1.3 \%$ were either in brick making or not in any formal employment (Table 1). Around fifty two percent $(51.87 \%)$ of the households had 4-6 occupants with a median of 4 and a range of $1-8$.

\section{Indoor adult mosquito collections}

Overall, 15,286 mosquitoes were collected over the two years using CDC light trap in 160 houses distributed over 16 study villages $($ mean $=4.35, \mathrm{SD}=11.48)$. Of all

Table 1 Characteristics of study population

\begin{tabular}{|c|c|c|c|}
\hline & Variable & Frequency & $\%$ \\
\hline \multirow[t]{7}{*}{ Education of $\mathrm{HH}$ head } & Primary school (Not completed) & 30 & 18.8 \\
\hline & Primary school (Completed) & 51 & 31.9 \\
\hline & Secondary school (Not completed) & 27 & 16.9 \\
\hline & Secondary school (Completed) & 25 & 15.6 \\
\hline & University/college & 15 & 9.4 \\
\hline & Informal education & 12 & 7.5 \\
\hline & Total households & 160 & 100 \\
\hline \multirow[t]{6}{*}{ Main occupation of $\mathrm{HH}$ head } & Student & 1 & 0.6 \\
\hline & Farming & 147 & 91.9 \\
\hline & Self-business & 8 & 5 \\
\hline & Unemployed & 2 & 1.3 \\
\hline & Brick making & 2 & 1.3 \\
\hline & Total households & 160 & 100 \\
\hline
\end{tabular}


mosquitoes collected, 2,872 (18.8\%) were anophelines (2,869 An. gambiae s.l., 1 Anopheles funestus and 2 other Anopheles spp), and 12,414 (81.2\%) were culicines. Of the total 12,414 culicines collected in the two years, $20.6 \%$ were collected from screened houses compared to $79.4 \%$ collected from unscreened (control) houses respectively. There was overall low number of Anopheles mosquitoes collected indoor in experimental houses compared to control houses during the sampling period despite nonsignificant difference in the mean number of mosquitoes (Additional file 1).

A total of 14,952 mosquitoes were unfed (2,749 $A n$. gambiae, 0 An. funestus, and 12,203 culicines), 311 mosquitoes were fed (106 An. gambiae, 0 An. funestus, and 205 culicines), 6 were half gravid (6 An. gambiae, 0 An. funestus, and 0 culicines), and 15 were gravid (8 An. gambiae, 1 An. funestus, and 6 culicines). Overall, among $A n$. gambiae collected, $92.6 \%$ were non-blood fed, $3.6 \%$ were blood fed and the remaining $0.5 \%$ were composed of gravid and half gravid females. However, irrespective of the species, more unfed, fed, half gravid and gravid mosquitoes were collected in the control than experimental arms of the study (Table 2).

Figure 3 gives the time series trend and comparison of the monthly collections of the anopheline mosquitoes. Baseline collections were done during the first nine months (i.e. January to September of 2017), and it cumulatively showed higher number of mosquitoes especially during the months of April and May. Further, the followup collection periods showed a gradual increase in the number of mosquitoes, which peaked around the months of July and August of the following year, before sudden decline to very low levels. Importantly, at most months, the total number of mosquitoes in the experimental group were lower than those in the control group.

\section{Impact of house screening on malaria prevalence}

Overall, malaria prevalence was 5.6\% (95\% CI: 4.2-7.5) $\mathrm{n}=1,918$, with baseline prevalence of $6.1 \%$ (95\% CI: $3.9-9.4), \mathrm{n}=481$ and $3^{\text {rd }}$ follow-up survey prevalence of 3.6\% (95\% CI: 2.0-6.8) $n=494$. At all the three follow-up survey points, house screening significantly reduced the malaria prevalence by $100 \%(p<0.001), 63.6 \%(p=0.026)$, and $100 \%(p<0.001)$ in the 1st, 2nd and 3rd follow-ups respectively. Analysis of the prevalence when baseline survey was not taken into account is also given in Table 3, and overall, there was no much noticeable difference in results with and without baseline survey. When baseline survey was not taken into account, greater impact of house screening in reducing malaria prevalence was observed at $80 \%(p=0.005)$ (Table 3$)$.

Figure 4 compares the malaria prevalence in both control and experimental groups at different survey points. Overall, house screening significantly reduced malaria prevalence by $54 \%(\mathrm{OR}=0.46,95 \% \mathrm{CI}: 0.24-0.87$, $p=0.017$ ), there were also significant impacts observed at each of the three follow-up survey points.

\section{Vector densities and malaria cases in relation to rainfall pattern}

Female Anopheles mosquitoes collected indoors per trap/ night reduced significantly from 2017 to 2018. In 2017, there was relatively high numbers of captured indoor malaria vectors that corresponded with a similar increase in recorded average rainfall especially for the months of March-June. The same year and months also recorded a

Table 2 Number of indoor adult mosquitoes collected in the study area, separated by species and physiological state

\begin{tabular}{|c|c|c|c|c|}
\hline Mosquito species & Unfed N (mean; SD) & Fed N (mean; SD) & Half gravid N (mean; SD) & Gravid N (mean; SD) \\
\hline \multicolumn{5}{|l|}{ Control } \\
\hline An. gambiae & $2208(0.78 ; S D=3.13)$ & $103(0.04 ; \mathrm{SD}=0.90)$ & $6(0 ; S D=0.11)$ & $8(0 ; S D=0.09)$ \\
\hline An. funestus & 0 & 0 & 0 & $1(0 ; S D=0.02)$ \\
\hline Other anopheles (unidentified) & 0 & 0 & 0 & 0 \\
\hline Culicines & $9658(3.40 ; \mathrm{SD}=8.88)$ & $197(0.07 ; \mathrm{SD}=1.01)$ & 0 & $3(0 ; \mathrm{SD}=0.03)$ \\
\hline \multicolumn{5}{|l|}{ Experimental } \\
\hline An.gambiae & $541(0.80 ; \mathrm{SD}=3.15)$ & $3(0 ; S D=0.09)$ & 0 & 0 \\
\hline An. funestus & 0 & 0 & 0 & 0 \\
\hline Other Anopheles & 0 & 0 & 0 & 0 \\
\hline Culicines & $2545(3.75 ; S D=12.82)$ & $8(0.01 ; S D=0.15)$ & 0 & $3(0 ; S D=0.09)$ \\
\hline \multicolumn{5}{|l|}{ Overall } \\
\hline An. gambiae & $2749(0.78 ; S D=3.14)$ & $106(0.03 ; \mathrm{SD}=0.81)$ & $6(0 ; S D=0.10)$ & $8(0 ; S D=0.08)$ \\
\hline An. funestus & 0 & 0 & 0 & $1(0 ; S D=0.02)$ \\
\hline Other Anopheles spp & 0 & 0 & 0 & 0 \\
\hline Culicines & $12,203(3.47 ; S D=9.76)$ & $205(0.06 ;$ SD = 0.91) & 0 & $6(0 ; S D=0.05)$ \\
\hline
\end{tabular}




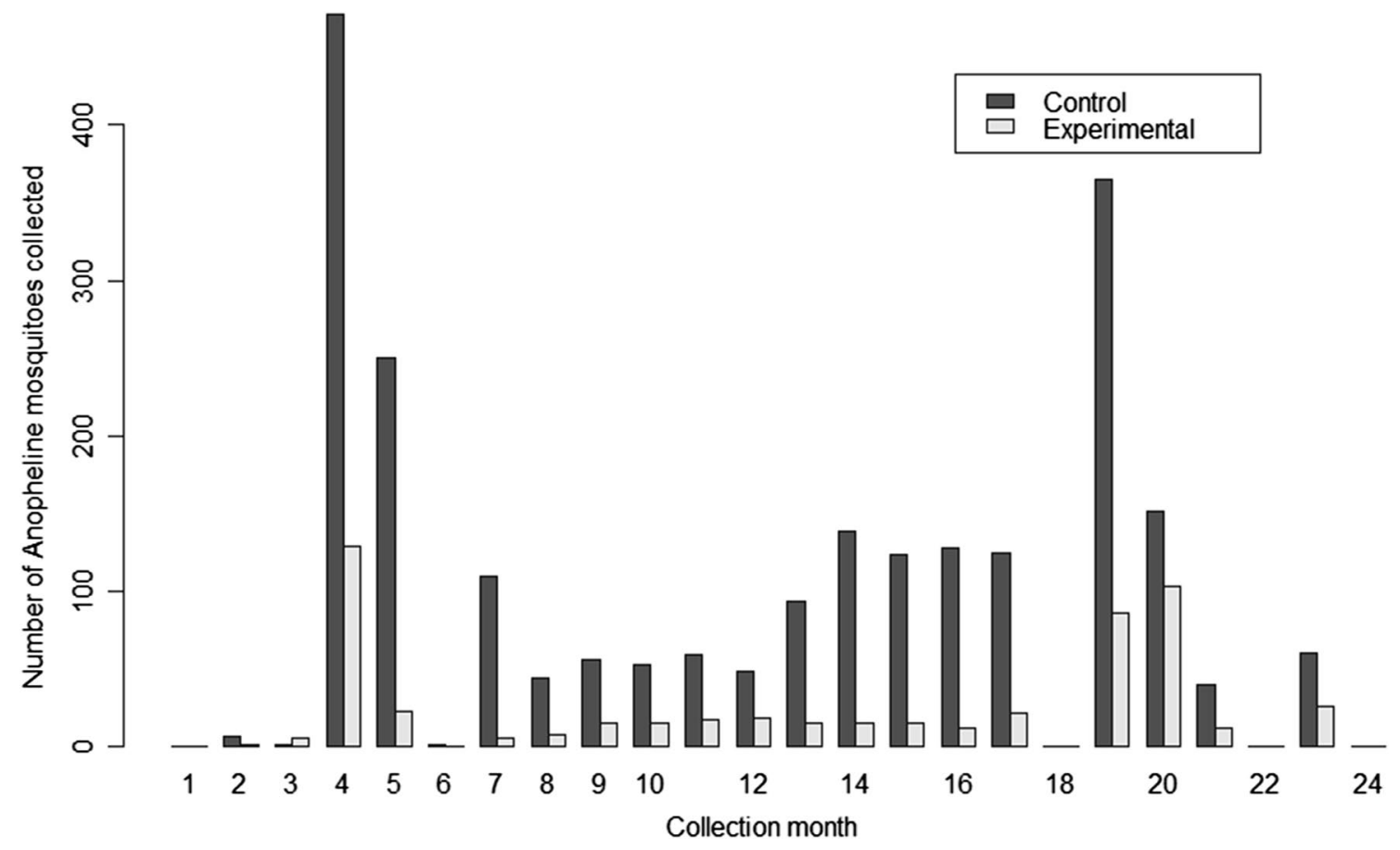

Fig. 3 Time series trend and comparison of the monthly collections of the anopheline mosquitoes for two years

Table 3 House eaves screening impact on malaria parasite prevalence rate in the study area

\begin{tabular}{|c|c|c|c|c|c|c|}
\hline \multirow[t]{2}{*}{ Characteristic } & \multirow[t]{2}{*}{ Baseline survey } & \multirow[t]{2}{*}{1 st follow-up } & \multirow[t]{2}{*}{ 2nd follow-up } & \multirow[t]{2}{*}{ 3rd follow-up } & \multicolumn{2}{|l|}{ Overall } \\
\hline & & & & & With baseline & Without baseline \\
\hline \multicolumn{7}{|c|}{ Malaria parasite prevalence, $\%(95 \%$ Cl)* } \\
\hline Control & $5.2(3.4-8.1)$ & $6.9(5.0-9.4)$ & $10.1(6.6-15.3)$ & $4.1(2.2-7.9)$ & $6.3(4.8-8.3)$ & $6.7(4.9-9.2)$ \\
\hline Experimental & $10(4.5-22.2)$ & 0 & $3.7(1.3-10.7)$ & 0 & $3.0(1.5-6.0)$ & $1.4(0.4-4.5)$ \\
\hline $\begin{array}{l}\text { Risk reduction, \% ( } p \\
\text { value) }\end{array}$ & Increase & $100 \%(p<0.001)$ & $63.6 \%(p=0.026)$ & $100 \%(p<0.001)$ & $52.4 \%(p=0.019)$ & $79.1 \%(p=0.006)$ \\
\hline Total prevalence & $6.1(3.9-9.4)$ & $4.6(3.5-5.9)$ & $8.2(5.1-13.2)$ & $3.6(2.0-6.8)$ & $5.6(4.2-7.5)$ & $5.4(3.9-7.5)$ \\
\hline \multicolumn{7}{|c|}{ House screening impact on malaria parasite prevalence, OR (95\% Cl), p value ${ }^{@}$} \\
\hline Control & Reference & & & & & \\
\hline Experimental & $\begin{array}{l}2.01(0.88-4.57) \\
p=0.096\end{array}$ & $0, p<0.001$ & $\begin{array}{l}0.35(0.14-0.85) \\
p=0.021\end{array}$ & $0, p<0.001$ & $\begin{array}{l}0.46(0.24-0.87) \\
p=0.017\end{array}$ & $\begin{array}{l}0.20(0.06-0.61) \\
p=0.005\end{array}$ \\
\hline
\end{tabular}

*Malaria parasite prevalence was calculated and 95\% confidence intervals estimated using binomial logistic regression model while accounting for house clustering

@ The impact of house screening on malaria prevalence was calculated and odds ratios (ORs) estimated using multilevel mixed effects logistic regression model while accounting for house clustering

similar increase in recorded malaria cases in the nearby Nyabondo Mission Hospital compared to year 2018 (Fig. 5). The high numbers of recorded malaria cases at the hospital for the months of September-November 2017 was attributed to national wide strike of nurses and clinicians working in government health facilities in the country. It was observed when the local government health facilities were not functioning, more local people sought health services from the mission hospital which also doubled as a referral facility serving people from other surrounding sub-counties. Comparatively, the year 2018 recorded reduced amount of rainfall, less numbers of malaria vectors.

\section{Discussion}

Housing structure has been shown to be one of the factors influencing indoor vector densities and malaria transmission $[21,24,25]$. Results from this study 

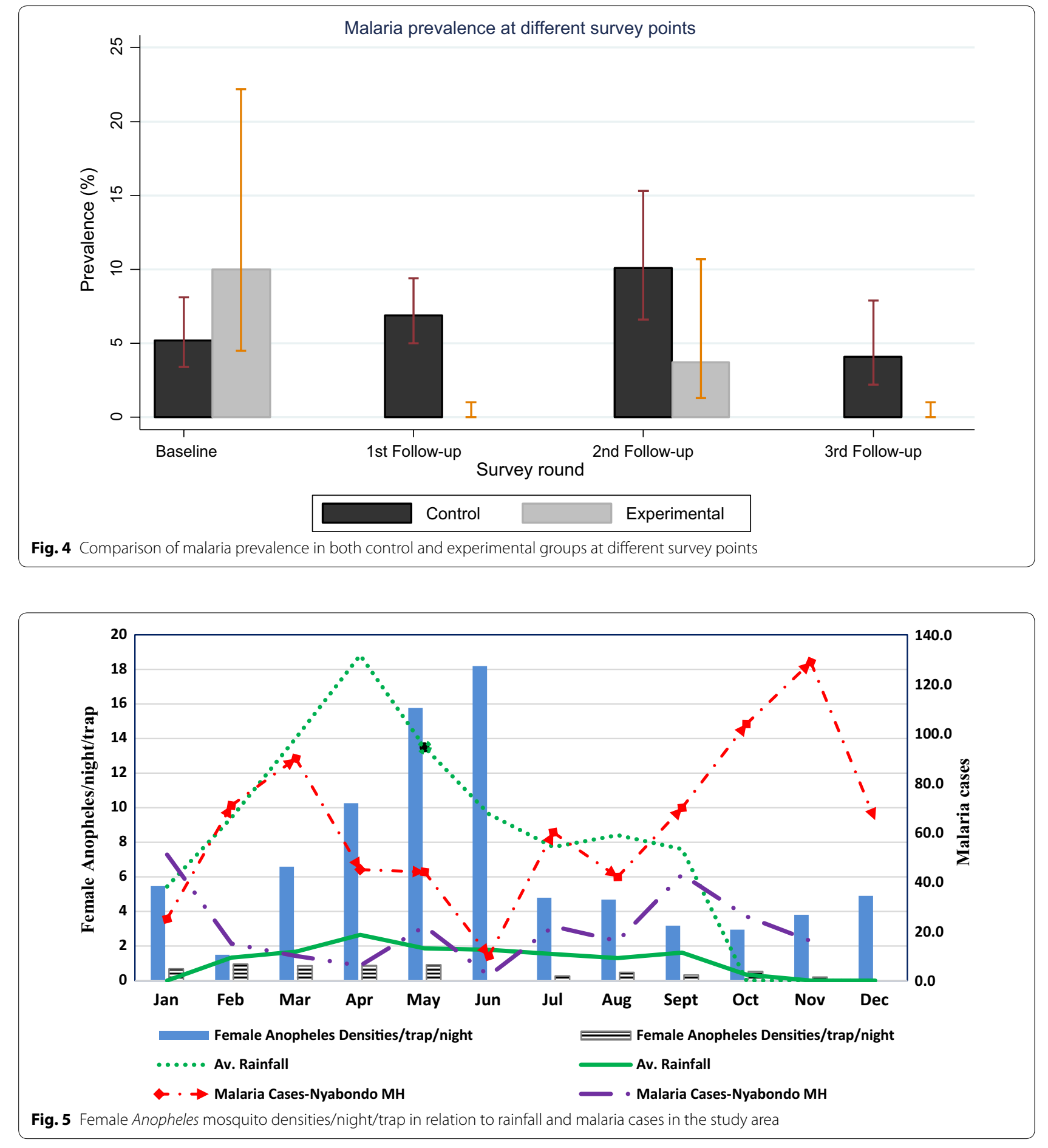

demonstrated that screening of house eaves has the potential of reducing the number of mosquitoes collected indoors and also malaria prevalence in a rural African setting of high malaria endemicity. These observations and those from prior assessment of community perception of house screening at the same study site [30] challenged a common notion elsewhere that screening interventions would be expensive, impractical and without benefit in rural African settings with houses that are constructed of mud walls and grass thatched roofs [45]. Poorly constructed houses with unscreened eave gaps would intuitively have high 
human-vector exposure compared to screened houses, resulting in a correspondingly higher risk of malaria transmission.

From this study, there was overall total reduction of Anopheles mosquitoes collected indoor in experimental houses compared to control houses during the study period. Similar observations have been made in the Gambia and Ethiopia where houses fitted with ceiling, door and window screens recorded a decrease in indoor resting mosquitoes [23, 47-49]. Other studies have demonstrated that major malaria vectors are predominantly endophagic, nocturnal and mainly enter houses through the eaves and more than $80 \%$ of malaria transmission occurs indoors, primarily at night or in the later part of the night $[49,50]$. Night time is, therefore, when most people are bitten and infected with malaria or certain other mosquito-borne pathogens such as those that cause lymphatic filariasis, transmitted by both anopheline and culicine mosquitoes. Of the total culicines collected in our study area, a large proportion was from the unscreened (control) houses. The importance of eaves as the preferred entry point for Anopheles mosquitoes has been recognized by the WHO since 1997 [18]. Thus, screening the gaps has the potential of lowering the occurrence of malaria, where mosquitoes usually feed on people indoors [48, 49, 51]. In a related survey in Baringo, Kenya, houses with closed eaves had a low mean number of mosquitoes compared to houses with open eaves [52]. Elsewhere in East Africa, poor housing construction was associated with increased malaria incidence in a cohort of young Ugandan children [53]. Also, in western Kenya, Atieli et al. 2009 demonstrated that house design modification by inclusion of a ceiling can reduce mosquito densities considerably [54].

In all the three follow-up survey points, house screening significantly reduced malaria prevalence. Screened houses recorded relatively low malaria prevalence rates in the study area compared to the control houses for the whole period. However, during the third prevalence survey (second follow up) that was conducted in JulyAugust 2018, both the intervention and control arms experienced an increase in prevalence rates. This could speculatively be partly attributed to less usage of personal protection measures during the hot seasons of the year when the rains subsided in the study area (Fig. 5). The potential effect of house screening in reducing malaria prevalence and incidences has been demonstrated in other related studies in Africa [21, 23, 46, 47, 51, 53]. A randomized trial in the Gambia also showed that screening was effective in reducing the level of anaemia in children [23] and in Dar es Salaam Tanzania, house screening contributed to a reduction in malaria transmission [46, 55].
Eave screening is most likely to be successful and accepted in areas where a large reduction in indoor biting is experienced by the occupants and also in households where people prefer not to use bed nets, or have stopped using them. Another potential advantage of house improvements and screening is the equity with which it protects all members of the household at all times while indoors, unlike LLINs which primarily give protection to those with a net during sleeping hours only. Nevertheless, eaves screening has also been found to affect compliance to LLNs use in areas where household members perceive that house screening offers them sufficient protection against mosquito bites [29]. Perhaps the greatest benefit to house screening would be its potential for integration with other vector control strategies like larval source management and bed net use. There is evidence that interventions which impede mosquito entry to houses could also protect inhabitants against vector-borne diseases such as leishmaniasis, dengue fever, yellow fever, zika virus, chikungunya, and lymphatic filariasis [26, 27].

Ecological and climatic factors have been reported to be important drivers of malaria transmission in subSaharan Africa [56-58]. Earlier studies in Western Kenya have attributed meteorological/climatic factors with the occurrence of $P$. falciparum malaria parasites, mosquito vector densities and risk of malaria transmission [56, 58, 59]. Vector availability, biting rates and parasite development are all influenced by climatic conditions as it relates to various Plasmodium species [56]. Factors such as temperature, humidity and rainfall directly impact the lifecycles of both vector and parasite [58]. Rainfall aids in accumulation of stagnant water, hence making the environment ideal for mosquito breeding sites, whereas, higher temperatures are associated with accelerated Plasmodium incubation period within mosquitoes $[57,58]$.

\section{Limitations of the study}

Doors and windows were not fitted with the screens. There is, therefore, a possibility that these could serve as mosquito entry points if left open during the night, thereby leading to a distortion of the results. However keeping doors and windows open at night is not common in the study area due to fear of theft. Through community engagements, household owners were also encouraged to close the windows and doors early in the evenings for purposes of the experiment. The imbalances between the arms could have been partly due to randomization error and use of CDC light traps in sampling indoor adult mosquitoes, which is associated with efficiency issues in estimating indoor vector densities at household level [60, 61]. Another limitation related to the number of malaria cases recorded at the mission hospital. It was not possible to determine the impact of the house screening in 
the community based on health facility data due to confounding factors such as climatic factors like rainfall, drought periods, strike action by $\mathrm{MOH}$ staff and the fact that the mission hospital was not the sole health service provider in the study area. The authors recommend further research on protective efficacy of house screening (doors, windows and eaves) before scaling up the intervention to the wider community in the study area. Among the households involved in the study accepted the intervention though further research is needed to assess the durability, cost-effectiveness and social acceptability of the intervention over time.

\section{Conclusion}

House eave screening is an effective and promising strategy for reducing indoor vector densities and malaria prevalence in high transmission rural areas. It also has the potential of being integrated with other control strategies in malaria endemic areas of Sub Saharan Africa.

\section{Supplementary information}

Supplementary information accompanies this paper at https://doi. org/10.1186/s12936-020-03413-3.

Additional file 1. Number of indoor adult mosquitoes collected in Nyabondo for two years, separated by species and the study arm.

\begin{abstract}
Abbreviations
CDC: Center for Disease Control; Cls: Confidence Intervals; DDT: DichloroDiphenyl-Trichloroethane; GEE: Generalized Estimating Equations; ICIPE: International Centre of Insect Physiology and Ecology; IRRs: Incidence Rate Ratios; IRS: Indoor Residual Spraying; ITNs: Insecticide-Treated Nets; IVM: Integrated Vector Management; KEMRI: Kenya Medical Research Institute; LLINs: Long-Lasting Insecticide-Treated Nets; $\mathrm{MOH}$ : Ministry of Health; NMCP: Malaria Control Programme; OR: Odds Ratio; RBM: Roll Back Malaria; RCT: Randomized Controlled Trial; RDTs: Rapid Diagnostic Tests; SD: Standard Deviation; SE: Standard Error; SERU: Scientific and Ethic Review Unit; WHO: World Health Organization; WHOPES: WHO Pesticide Evaluation Scheme.
\end{abstract}

\section{Acknowledgements}

We would like to thank all the household owners for their hospitality, cooperation and consent to participate throughout the course of this study. We are also grateful to the community youth group, MOCON for support with the house screening. We acknowledge invaluable inputs by Polycarp Aduogo, George Oliech, Simon Cheruiyot, the nurses and laboratory technician from the Sub-County Ministry of Health. Final vote of thanks goes to both Directors of ICIPE and KEMRI, and Biovision for making this study possible.

\section{Authors' contributions}

PNN participated in the study design, data collection, analyses, and drafting the manuscript in consultation with the other authors. CO participated in cleaning, cross checking, analysing and interpretation of statistical data. CM participated in conception of study design. CMM conceived the study, supervised it, reviewed, guided and participated in drafting the manuscript. All authors read and approved the final manuscript.

\section{Funding}

This research work was funded by Biovision (BV) Foundation, Project Number BV HH-07 / 2016-18, and core financial assistance to the International Centre of Insect Physiology and Ecology (icipe) provided by UK's Department for International Development (DFID), the Swedish International Development Cooperation Agency (Sida), the Swiss Agency for Development and
Cooperation (SDC), the German Federal Ministry for Economic Cooperation and Development (BMZ), and the Kenyan and Ethiopian Governments.

\section{Availability of data and materials}

The data and materials used for this study are available from the corresponding author upon request.

\section{Ethical approval and consent to participate}

The study ethical approval was granted by Kenya Medical Research Institute (KEMRI) through the /Scientific and Ethic Review Unit (SERU) protocol number 2675 as part of the Integrated Vector Management for Sustainable Malaria Control in East Africa study reference number KEMRI/RES/7/3/1. Objective of the study, confidentiality of the information, benefits and possible risks associated with the study were explained to the participants before commencement.Written and oral informed consent was obtained from all participants in this study, after being provided with all necessary information regarding goals, objective, benefits associated with the study.After consenting, the head of the house was asked to sign two copies of the consent forms, of which, one remained with the head of the house and the other copy was kept by the study investigator.

\section{Consent for publication}

Not applicable.

\section{Competing interests}

The authors declare that they have no competing interests.

\section{Author details}

${ }^{1}$ International Centre of Insect Physiology and Ecology (ICIPE), PO Box 30772, Nairobi, Kenya. ${ }^{2}$ Jomo Kenyatta University of Agriculture and Technology, School of Public Health, PO Box 62000, Nairobi, Kenya. ${ }^{3}$ Eastern and Southern Africa Centre of International Parasite Control (ESACIPAC), Kenya Medical Research Institute (KEMRI), Nairobi, Kenya. ${ }^{4}$ KEMRI-Wellcome Trust Research Programme, Public Health Unit, PO Box 43640 - 00100, Nairobi, Kenya. ${ }^{5}$ University of Pretoria Institute for Sustainable Malaria Control (UP ISMC, School of Health Systems and Public Health, University of Pretoria, Private Bag X363, Pretoria 0001, South Africa.

Received: 3 December 2019 Accepted: 10 September 2020

Published online: 19 September 2020

\section{References}

1. Republic of Kenya (RoK). Malaria Operational Plan FY 2018. US. President's Malaria Initiatives. Nairobi: Ministry of Health (MOH); 2018.

2. Cotter C, Sturrock HJW, Hsiang MS, Liu J, Phillips AA, Hwang J, et al. The changing epidemiology of malaria elimination: new strategies for new challenges. Lancet. 2013;382:900-11.

3. Kapesa A, Kweka EJ, Atieli H, Afrane YA, Kamugisha E, Lee MC, et al. The current malaria morbidity and mortality in different transmission settings in Western Kenya. PLoS ONE. 2018;13:e0202031.

4. Republic of Kenya (RoK). Kenya Malaria Strategy 2019-2023. Nairobi: National Malaria Control Programme, Ministry of Health; 2019.

5. WHO. World malaria report. Geneva: World Health Organization; 2016

6. WHO. World malaria report. Geneva: World Health Organization; 2018.

7. Bhatt S, Weiss DJ, Mappin B, Dalrymple U, Cameron E, Bisanzio D, et al. Coverage and system efficiencies of insecticide-treated nets in Africa from 2000 to 2017. Elife. 2015;4:e09672.

8. WHO. Global plan for insecticide resistance management in malaria vectors. World Health Organization: Geneva; 2012.

9. Bhatt S, Gething P. Insecticide-treated nets (ITNs) in Africa 2000-2016: coverage, system efficiency and future needs for achieving international targets. Malar J. 2014;13(Suppl 1):O29.

10. Barreaux P, Barreaux AMG, Sternberg ED, Suh E, Waite JL, Whitehead SA, et al. Priorities for broadening the malaria vector control tool kit. Trends Parasitol. 2017;33:763-74.

11. Ranson H, N'Guessan R, Lines J, Moiroux N, Nkuni Z, Corbel V. Pyrethroid resistance in African anopheline mosquitoes: what are the implications for malaria control? Trends Parasitol. 2011;27:91-8. 
12. WHO. Global strategic framework for integrated vector management. Geneva: World Health Organization; 2004.

13. WHO. Handbook on integrated vector management (IVM). Geneva: World Health Organization; 2012.

14. Beier JC, Keating J, Githure JI, Macdonald MB, Impoinvil DE, Novak RJ. Integrated vector management for malaria control. Malar J. 2008;7(Suppl 1):S4.

15. Mutero C, Mbogo C, Mwangangi J, Imbahale S, Kibe L, Orindi B, et al. An assessment of participatory integrated vector management for malaria control in Kenya. Environ Health Perspect. 2015;123:1145-51.

16. Boyd MF. The influence of obstacles unconsciously erected against Anophelines (housing and screening) upon the incidence of malaria. Am J Trop Med Hyg. 1926;s1-6:157-60.

17. Stevens PA. Environmental management activities in malaria control in Africa. Bull World Health Organ. 1984;62(Suppl):77-80.

18. Rozendaal A. Vectors control: Methods for use by individuals and communities. Geneva: WHO; 1997.

19. Keiser J, Singer BH, Utzinger J. Reducing the burden of malaria in different eco epidemiological settings with environmental management: a systematic review. Lancet Infect Dis. 2005:5:695-708.

20. Mburu MM, Juurlink M, Spitzen J, Moraga P, Hiscox A, Mzilahowa T, et al. Impact of partially and fully closed eaves on house entry rates by mosquitoes. Parasit Vectors. 2018;11:383.

21. Tusting LS, Ippolito M, Kleinschmidt I, Willey B, Gosling R, Dorsey G, et al. The evidence for improving housing to reduce malaria: a systematic review and meta-analysis. Malar J. 2015;14:209.

22. RBM. Housing and malaria consensus statement. Geneva: Roll Back Malaria Partnership; 2015.

23. Kirby MJ, Ameh D, Bottomley C, Green C, Jawara M, Milligan PJ, et al. Effect of two different house screening interventions on exposure to malaria vectors and on anaemia in children in The Gambia: a randomised controlled trial. Lancet. 2009;374:998-1009.

24. Tusting LS, Bottomley C, Gibson H, Kleinschmidt I, Tatem AJ, Lindsay SW, et al. Housing improvements and malaria risk in subSaharan Africa: a multi- country analysis of survey data. PLoS Med. 2017;14:e1002234.

25. Carter AD. Are housing improvements an effective supplemental vector control strategy to reduce malaria transmission? A systematic review. School of Public Health, Georgia State University; 2014.

26. Ogoma SB, Lweitoijera DW, Ngonyani H, Furer B, Russell TL, Mukabana WR, et al. Screening mosquito house entry points as a potential method for integrated control of endophagic filariasis, arbovirus and malaria vectors. PLoS Negl Trop Dis. 2010;4:e773.

27. Wilson AL, Dhiman R, Kitron U, Scott TW, van den Berg H, Lindsay SW. Benefit of insecticide-treated nets, curtains and screening on vector borne diseases, excluding malaria: a systematic review and metaanalysis. PLoS Negl Trop Dis. 2014;8:e3228.

28. Lwetoijera DW, Kiware SS, Mageni ZD, Dongus S, Harris C, Devine GJ, et al. A need for better housing to further reduce indoor malaria transmission in areas with high bed net coverage. Parasit Vectors. 2013;6:57.

29. Kirby MJ, Bah P, Jones $\mathrm{COH}$, Kelly AH, Jasseh M, Lindsay SW. Social acceptability and durability of two different house screening interventions against exposure to malaria vectors, Plasmodium falciparum infection, and anemia in children in The Gambia, West Africa. Am J Trop Med Hyg. 2010;83:965-72.

30. Ng'ang'a PN, Mutunga J, Oliech G, Mutero CM. Community knowledge and perceptions on malaria prevention and house screening in Nyabondo, Western Kenya. BMC Public Healt. 2019;19:423.

31. Kenya National Bureau of Statistics (KNBS). 2019 Kenya population and housing census. Kenya National Bureau of Statistics (KNBS), vol. I. Nairobi, Kenya; 2019. ISBN: 978-9966-102-09-6.

32. Imbahale SS, Abonyo OK, Aduogo OP, Githure JI, Mukabana WR. Conflict between the need for income and the necessity of controlling endemic malaria. J Ecosystem Ecography. 2013;3:129.

33. National Malaria Control Programme, Ministry of Health. The epidemiology and control profile of malaria in Kenya: reviewing the evidence to guide the future of vector control. Nairobi: National Malaria Control Programme, Ministry of Health; 2016.

34. Howard AF, Omlin FX. Abandoning small-scale fish farming in western Kenya leads to higher malaria vector abundance. Acta Trop. 2008:105:67-73.
35. Imbahale SS, Paaijmans KP, Mukabana WR, Lammeren R, Githeko AK, Takken W. A longitudinal study on Anopheles mosquito larval abundance in distinct geographical and environmental settings in western Kenya. Malar J. 2011;10:81.

36. Kenya National Bureau of Statistics (KNBS), and ICF International. Kenya Malaria Indicator Survey 2015. Nairobi, Kenya, and Rockville, Maryland, USA: NMCP, KNBS, and ICF International National Treasury; 2016.

37. WHO. How to design vector control efficacy trials, guidance on phase III vector control field trial design. Geneva: World Health Organization; 2017.

38. Kramer RA, Mboera LEG, Senkoro K, Lesser A, Shayo EH, Paul CJ, et al. A randomized longitudinal factorial design to assess malaria vector control and disease management interventions in rural Tanzania. Int J Environ Res Public Health. 2014;11:5317-32.

39. Coetzee M, Craig M, Le-Sueur D. Distribution of Africa malaria mosquitoes belonging to the Anopheles gambiae complex. Parasitol Today. 2000;16:74-7.

40. Gillies MT, De Meillon B. The anophelinae of Africa south of the Sahara (Ethiopian Zoogeographical Region). Johannesburg: South African Institute for Medical Research; 1968. ISBN: 19692900946.

41. Republic of Kenya (RoK). Ministry of Public Health and Sanitation. National Guidelines for the Diagnosis, Treatment and Prevention of Malaria in Kenya. Nairobi: Ministry of Public Health and Sanitation, Division of Malaria Control; 2010.

42. WHO. How to use a rapid diagnostic test (RDT): a guide for training at a village and clinic level (Modified for training in the use of the Generic Pf-Pan Test for falciparum and non-falciparum malaria), vol. 12. Geneva: World Health Organization; 2010.

43. WHO. Malaria rapid diagnostic test performance: results of WHO product testing of malaria RDTs: round 8 (2016-2018). Geneva: World Health Organization; 2018.

44. Liang $K Y$, Zeger SL. Longitudinal data analysis using generalized linear models. Biometrika. 1986;73:13-22.

45. Wanzirah H, Tusting LS, Arinaitwe E, Katureebe A, Maxwell K, Rek J, et al. Mind the gap House structure and the risk of malaria in Uganda children. PLOS ONE. 2015;10:e0117396.

46. Liu JX, Bousema T, Zelman B, Gesase S, Hashim R, Maxwell C, et al. Is housing quality associated with malaria incidence among young children and mosquito vector numbers? Evidence from Korogwe. Tanzania PLoS ONE. 2014;9:e87358.

47. Kirby MJ, Green C, Milligan PM, Sismanidis C, Jasseh M, Conway D, et al. Risk factors for house-entry by malaria vectors in a rural town and satellite villages in The Gambia. Malar J. 2008;7:2.

48. Lindsay SW, Jawara M, Paine K, Pinder M, Walraven GE, Emerson PM. Changes in house design reduce exposure to malaria mosquitoes. Trop Med Int Health. 2003;8:512-7.

49. Massebo F, Lindtjørn B. The effect of screening doors and windows on indoor density of Anopheles arabiensis in South-West Ethiopia: a randomized trial. Malar J. 2013;12:319.

50. Huho B, Briet O, Seyoum A, Sikaala C, Bayoh N, Gimnig J, et al. Consistently high estimates for the proportion of human exposure to malaria vector populations occurring indoors in rural Africa. Int J Epidemiol. 2013;42:235-47.

51. Bradley J, Rehman AM, Schwabe C, Vargas D, Monti F, Ela C, et al. Reduced prevalence of malaria infection in children living in houses with window screening or closed eaves on Biko Island. Equatorial Guinea PLoS ONE. 2013;8:e80626

52. Ondiba IM, Oyieke FA, Ong'amo GO, Olumula MM, Nyamongo IK, Estambale BBA. Malaria vector abundance is associated with house structures in Baringo County. Kenya PLoS ONE. 2018;13:e0198970.

53. Snyman K, Mwangwa F, Bigira V, Kapisi J, Clark TD, Osterbauer B, et al. Poor housing construction associated with increased malaria incidence in a cohort of young Ugandan children. Am J Trop Med Hyg. 2015;92:1207-13.

54. Atieli H, Menya D, Githeko A, Scott T. House design modifications reduce indoor resting malaria vector densities in rice irrigation scheme area in western Kenya. Malar J. 2009:8:108.

55. Geissbühler Y, Kannady K, Chaki PP, Emidi B, Govella NJ, et al. Microbial larvicide application by a large-scale, community-based program reduces malaria infection prevalence in urban Dares Salaam, Tanzania. PLoS ONE. 2009;4:e5107. 
56. Shanks GD, Hay SI, Stern DI, Biomndo K, Snow RW. Meteorologic influences on Plasmodium falciparum malaria in the Highland Tea Estates of Kericho. Western Kenya Emerg Infect Dis. 2002;8:1404-8.

57. Abeku TA, van Oortmarssen GJ, Borsboom G, de Vlas SJ, Habbema JD. Spatial and temporal variations of malaria epidemic risk in Ethiopia: factors involved and implications. Acta Trop. 2003;87:331-40.

58. Zhou G, Minakawa N, Githeko AK, Yan G. Climate variability and malaria epidemics in the highlands of East Africa. Trends Parasitol. 2005;21:54-6.

59. Imbahale SS, Mukabana WR, Orindi B, Githeko AK, Takken W. Variation in malaria transmission dynamics in three different sites in Western Kenya. J Trop Med. 2012;2012:912408.

60. Mbogo CN, Glass GE, Forster D, Kabiru EW, Githure Jl, Ouma JH, et al. Evaluation of light traps for sampling anopheline mosquitoes in Kilifi, Kenya. J Am Mosq Control Assoc. 1993;9:260-3.
61. Fornadel CM, Norris LC, Norris DE. Centers for disease control light traps for monitoring human biting rates in an area with low vector density and high insecticide-treated bed net use. Am J Trop Med Hyg 2010;83:838-42.

\section{Publisher's Note}

Springer Nature remains neutral with regard to jurisdictional claims in published maps and institutional affiliations.
Ready to submit your research? Choose BMC and benefit from:

- fast, convenient online submission

- thorough peer review by experienced researchers in your field

- rapid publication on acceptance

- support for research data, including large and complex data types

- gold Open Access which fosters wider collaboration and increased citations

- maximum visibility for your research: over $100 \mathrm{M}$ website views per year

At BMC, research is always in progress.

Learn more biomedcentral.com/submissions 